\title{
Two-dimensional metal-organic framework nanosheets as a dual ratiometric and turn-off luminescent probe
}

Rawan Al Natour ${ }^{\ddagger}$, Zeinab Kara Ali ${ }^{\ddagger}$, Abdeljalil Assoud ${ }^{\S}$ and Mohamad Hmadeh**

'Chemistry Department, American University of Beirut, P.O.Box 11-0236, Riad El-Solh, 11072020 Beirut, Lebanon.

${ }^{\S}$ Department of Chemistry, University of Waterloo, Waterloo, Ontario N2L 3G1, Canada.

Mohamad.hmadeh@aub.edu.lb 
Table S1. Crystal data and structure refinement of AUBM-6

\section{AUBM-6}

\begin{tabular}{|c|c|}
\hline Empirical formula & $\mathrm{C}_{17} \mathrm{H}_{17} \mathrm{Cu} \mathrm{N}_{3} \mathrm{O}_{6}$ \\
\hline Formula weight & 413.80 \\
\hline Temperature, $\mathrm{K}$ & $296(2)$ \\
\hline Wavelength, $\AA$ & 0.71073 \\
\hline Crystal system & Orthorhombic \\
\hline Space group & $\mathrm{Pca}_{1}$ \\
\hline a, $\AA$ & $23.8349(6)$ \\
\hline $\mathrm{b}, \AA$ & $5.80370(10)$ \\
\hline $\mathrm{c}, \AA$ & $13.1873(3)$ \\
\hline$\alpha, \operatorname{deg}$ & 90 \\
\hline$\beta, \operatorname{deg}$ & 90 \\
\hline$\gamma, \operatorname{deg}$ & 90 \\
\hline Volume, $\AA^{3}$ & $1824.21(7)$ \\
\hline $\mathrm{Z}$ & 4 \\
\hline Density (calculated), $\mathrm{Mg} / \mathrm{m}^{3}$ & 1.507 \\
\hline Absorption coefficient, $\mathrm{mm}^{-1}$ & 1.235 \\
\hline $\mathrm{F}(000)$ & 832 \\
\hline Crystal size, $\mathrm{mm}^{3}$ & $0.150 \times 0.150 \times 0.150$ \\
\hline Theta range for data collection & 3.419 to $25.997^{\circ}$. \\
\hline Index ranges & $-25<=\mathrm{h}<=29,-7<=\mathrm{k}<=6,-16<=1<=15$ \\
\hline Reflections collected & 9627 \\
\hline Independent reflections & $3523[\mathrm{R}(\mathrm{int})=0.0369]$ \\
\hline Completeness to theta $=25.242^{\circ}$ & $99.7 \%$ \\
\hline Absorption correction & Semi-empirical from equivalents \\
\hline Max./min. transmission & $0.7460 / 0.7111$ \\
\hline
\end{tabular}


Refinement method

Data / restraints / parameters

Goodness-of-fit on $\mathrm{F}^{2}$

Final R indices $[\mathrm{I}>2 \sigma(\mathrm{I})]$

$\mathrm{R}$ indices (all data)

Absolute structure parameter

Extinction coefficient

Largest diff. peak and hole e $\AA^{-3}$
Full-matrix least-squares on $\mathrm{F}^{2}$

$3523 / 31 / 235$

1.371

$\mathrm{R}_{1}=0.0540, \mathrm{wR}_{2}=0.1364$

$\mathrm{R}_{1}=0.0573, \mathrm{wR}_{2}=0.1380$

$0.099(11)$

N/A
A

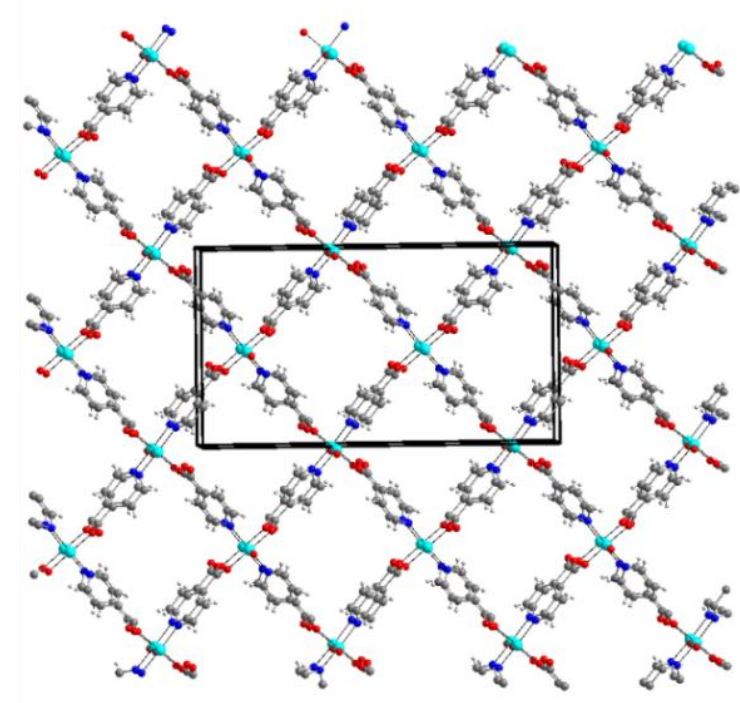

B

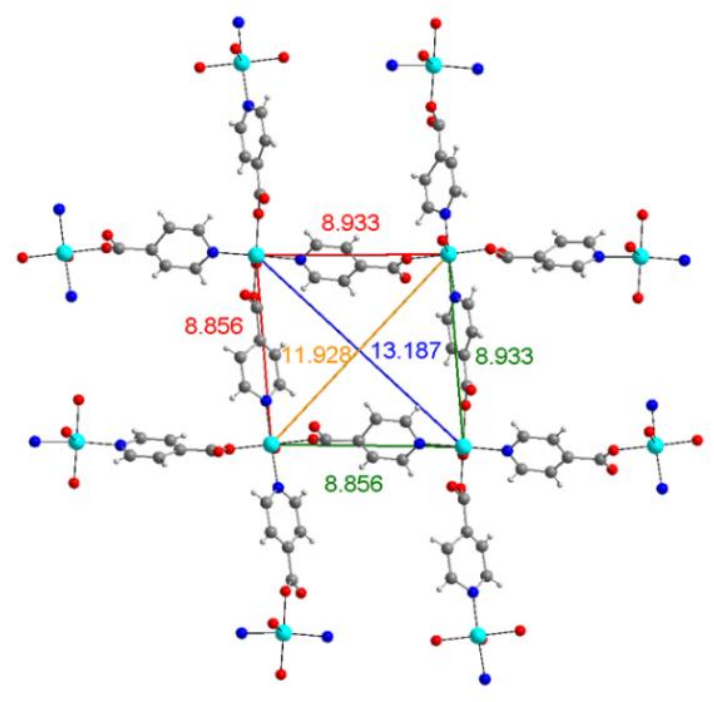

Fig. S1. (A) Crystallographic unit cell of AUBM-6 (B) Diagonal and side dimensions of 1-D channels of AUBM-6 


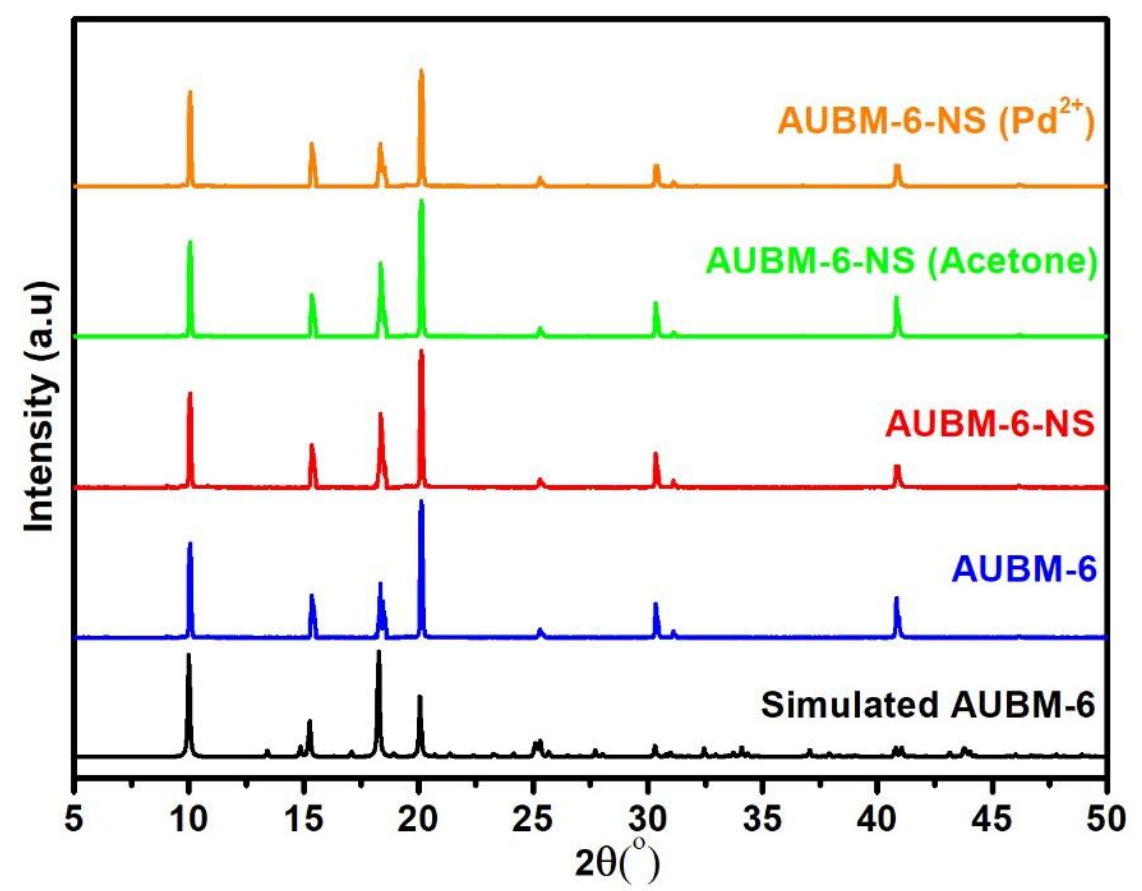

Fig. S2. Simulated and experimental PXRD patterns of AUBM-6 and AUBM-6NS before and after acetone and $\mathrm{Pd}^{2+}$ sensing

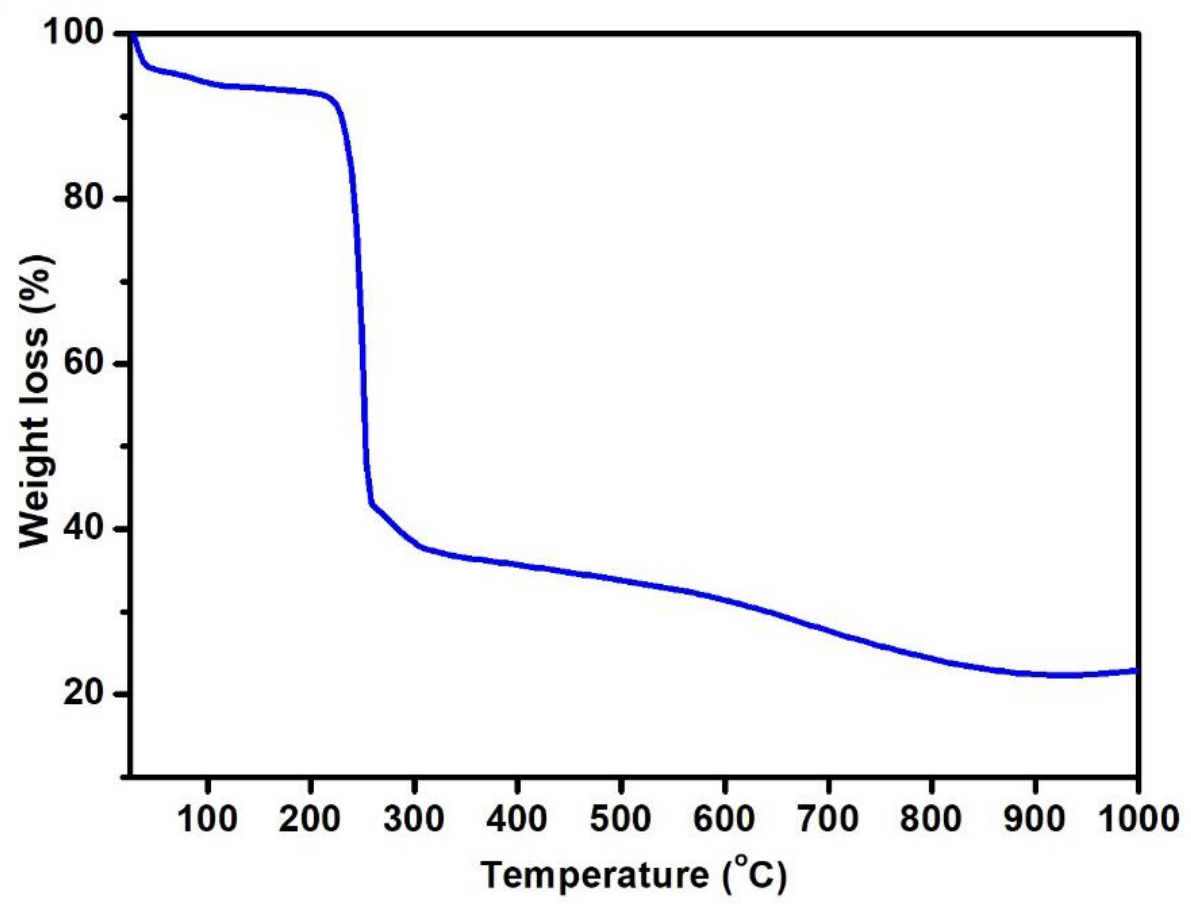

Fig. S3. Thermogravimetric analysis of AUBM-6 


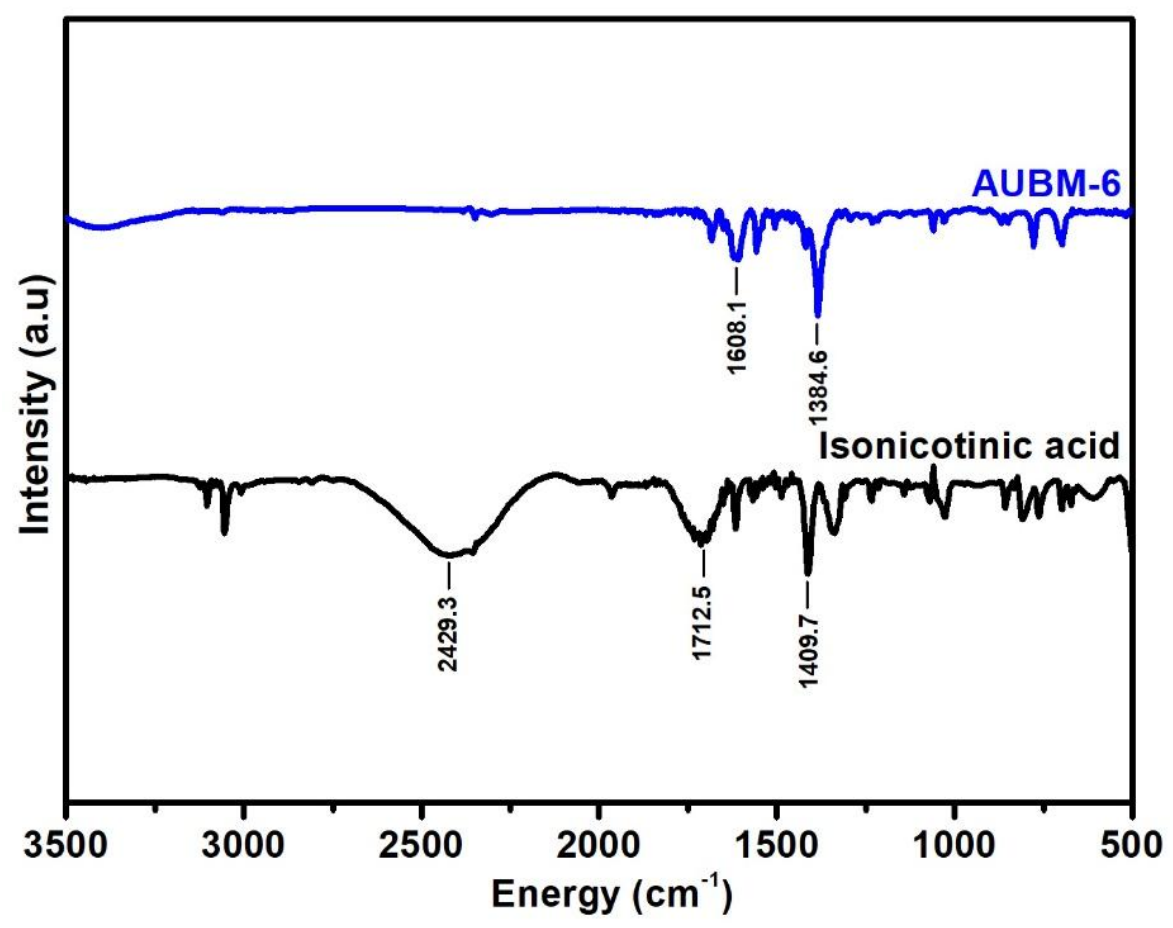

Fig. S4. FT-IR spectrum of INA ligand and AUBM-6.

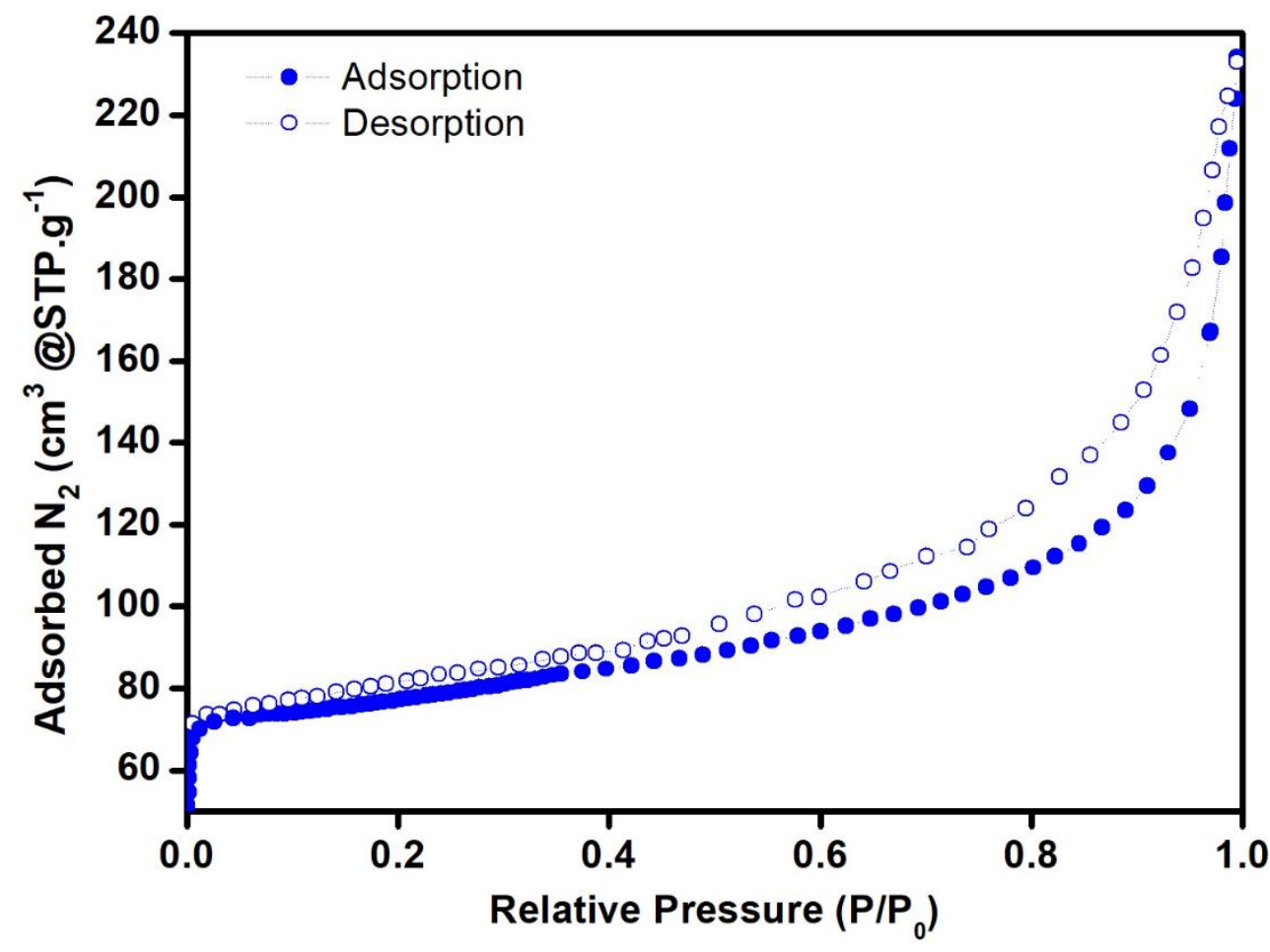

Fig. S5. Nitrogen adsorption/desorption isotherm at 77K of AUBM-6. 

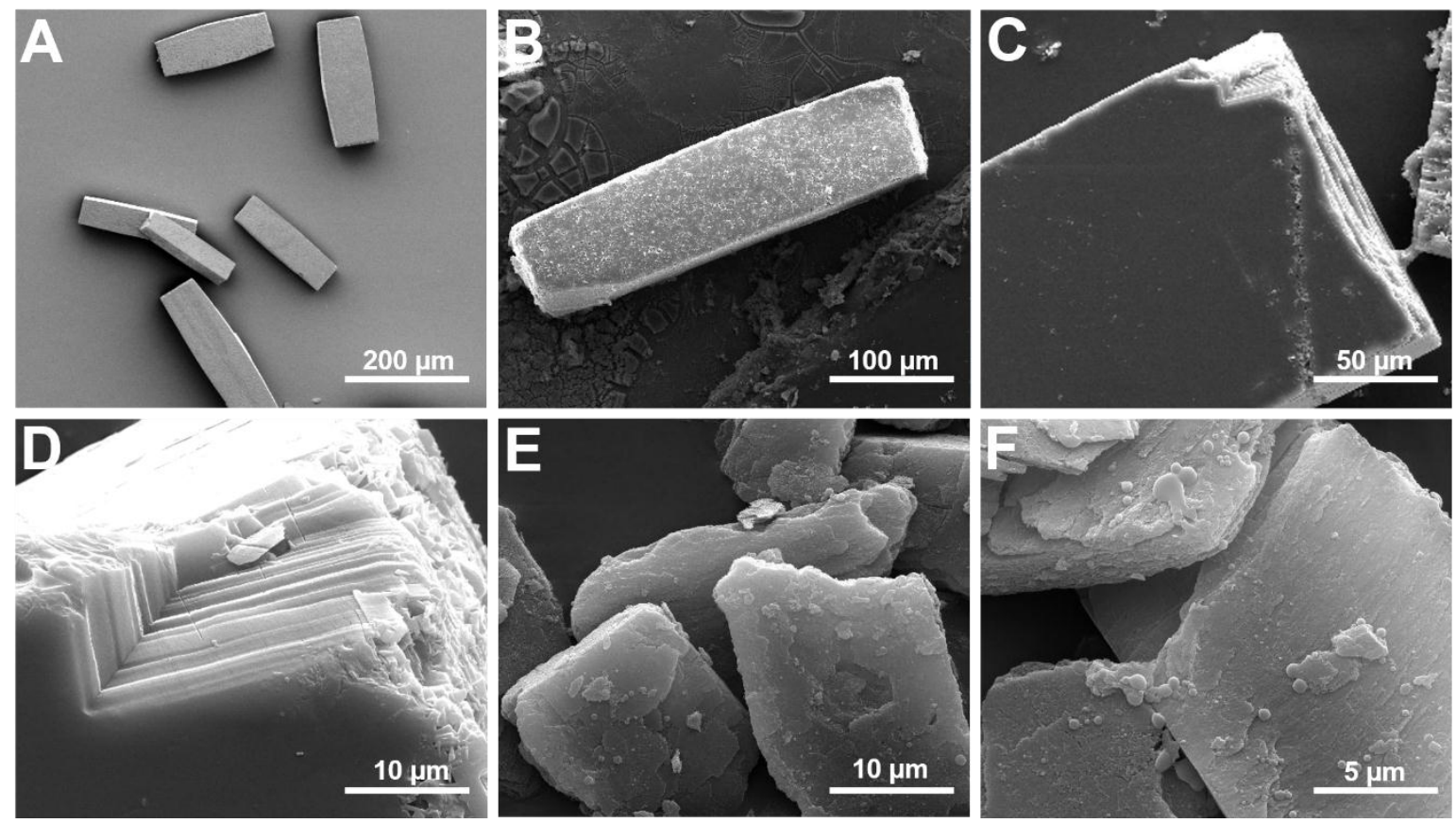

Fig. S6. SEM images of (A) Bulk crystals of AUBM-6 (B) Single crystal of AUBM-6 (C)(D) Layered morphology of AUBM-6 (E)(F) Exfoliated few layer nanosheets of AUBM-6-NS

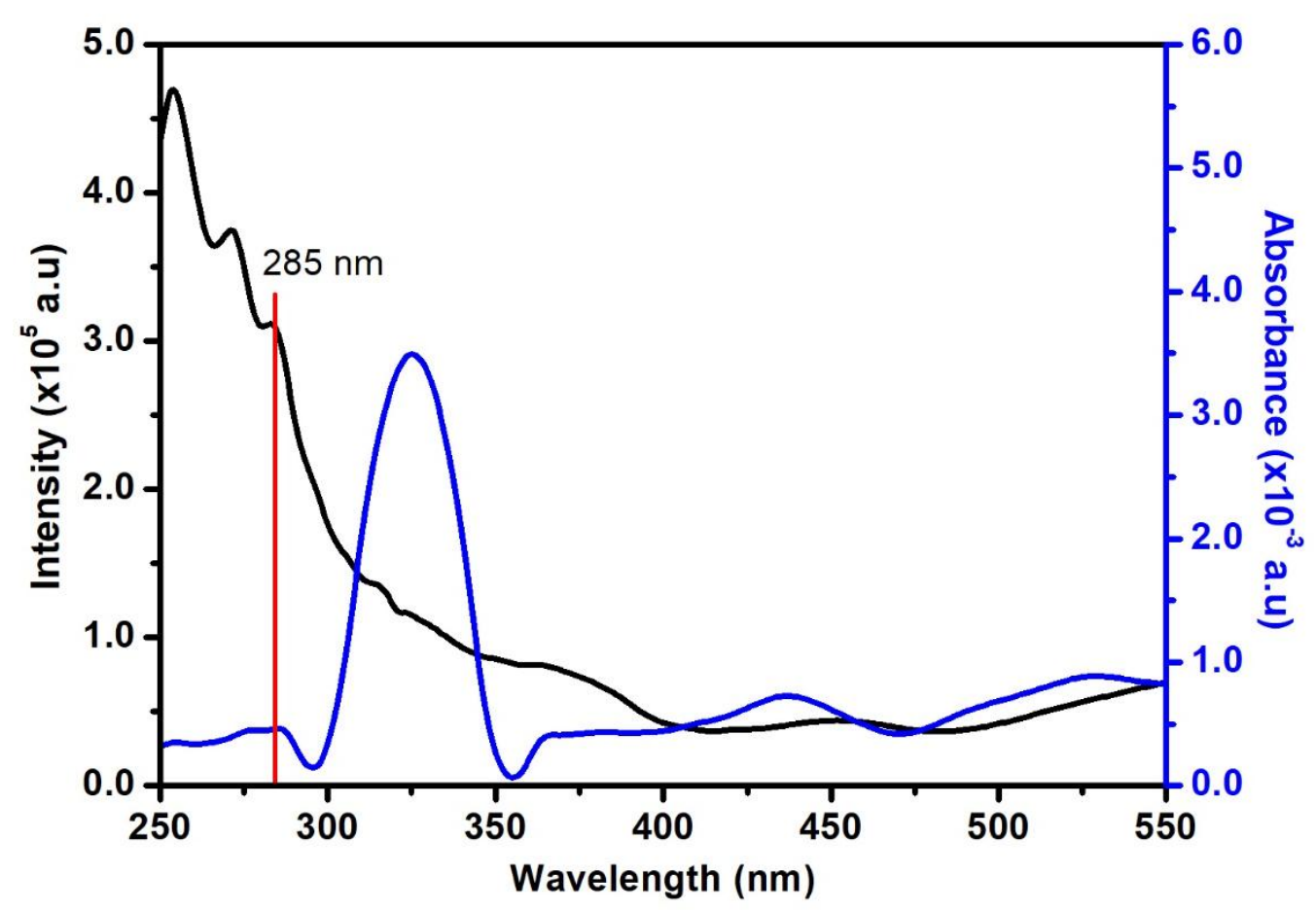

Fig. S7. UV-Vis spectrum of blank acetone (blue) and excitation spectrum of AUBM-6 (black). 


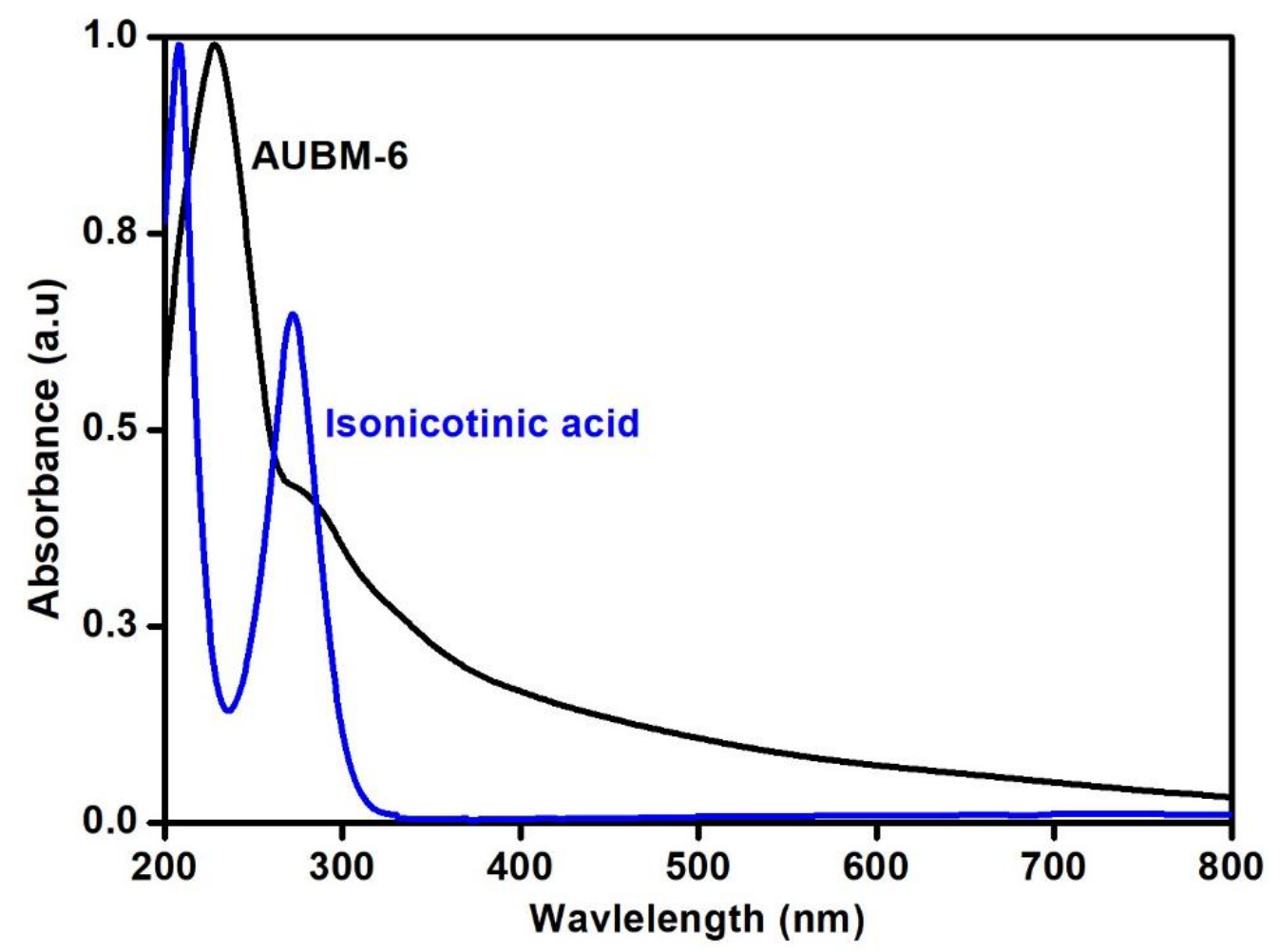

Fig. S8. UV-Vis Spectrum of INA ligand and AUBM-6 in acetonitrile $\mathrm{CH}_{3} \mathrm{CN}$.

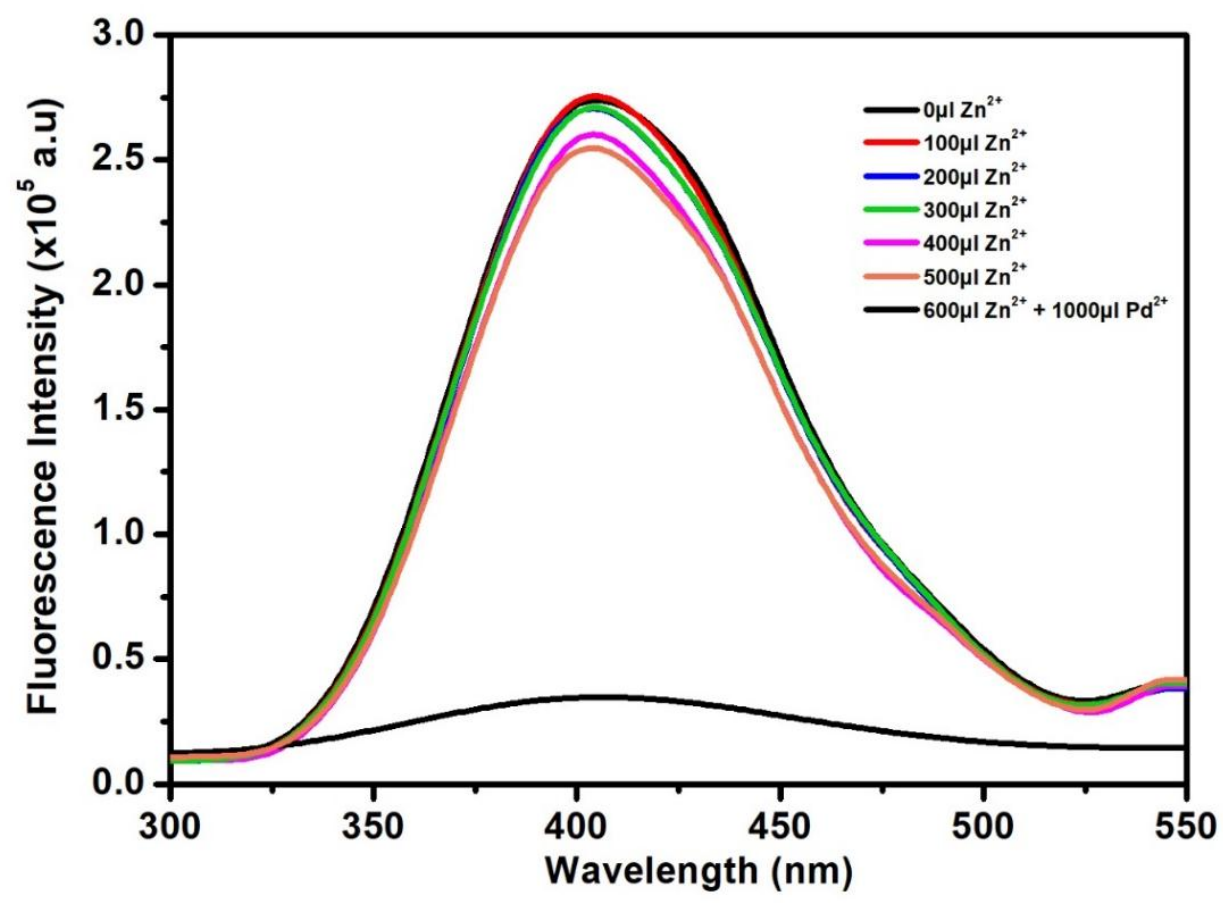

Fig. S9. The change in fluorescence intensity of AUBM-6-NS in acetone upon addition of $\mathrm{Zn}^{2+}$ solution followed by $\mathrm{Pd}^{2+}$ solution 


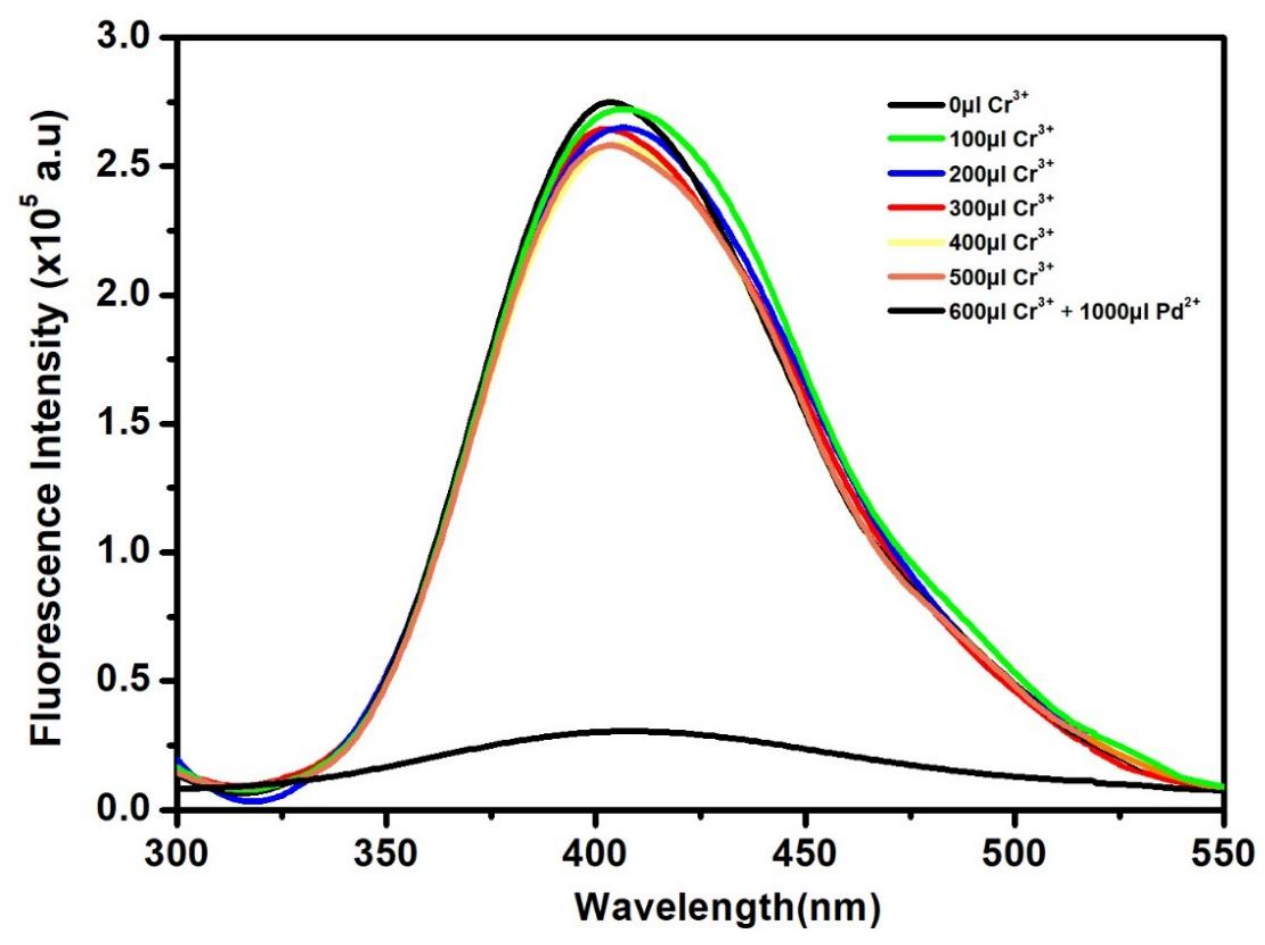

Fig. S10. The change in fluorescence intensity of AUBM-6-NS in acetone upon addition of $\mathrm{Cr}^{3+}$ solution followed by $\mathrm{Pd}^{2+}$ solution

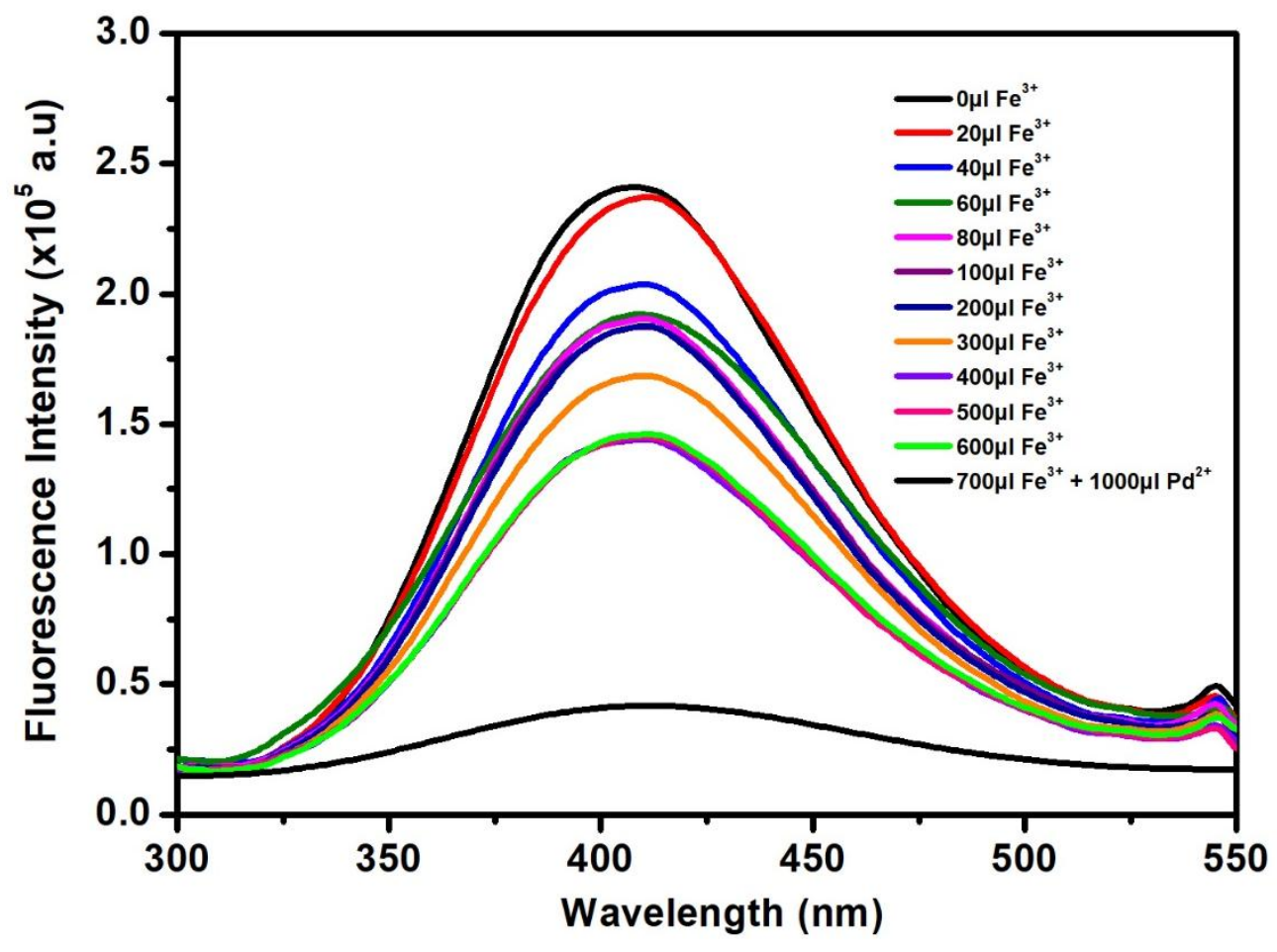

Fig. S11. The change in fluorescence intensity of AUBM-6-NS in acetone upon addition of $\mathrm{Fe}^{3+}$ solution followed by addition of $\mathrm{Pd}^{2+}$ solution 


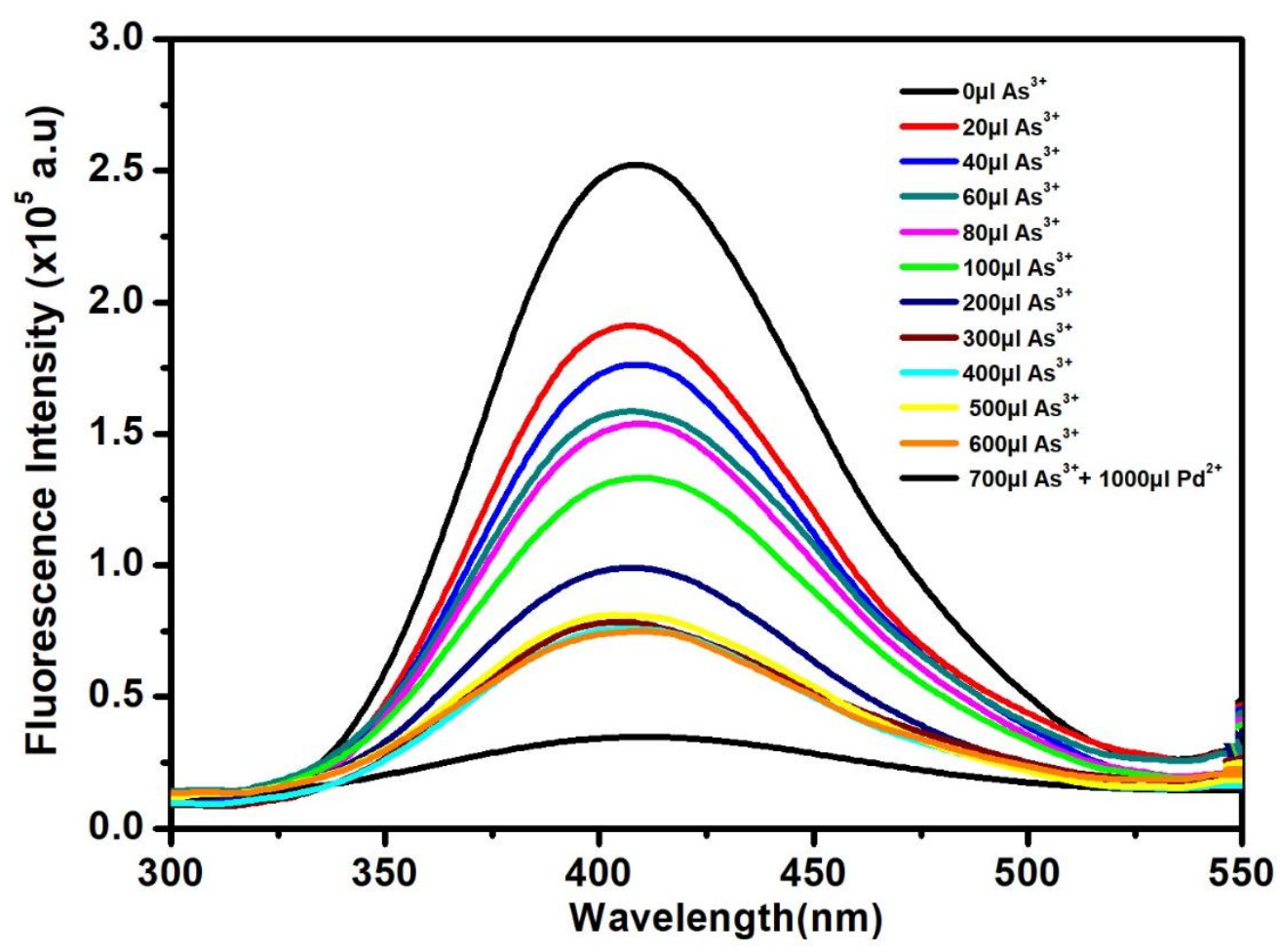

Fig. S12. The change in fluorescence intensity of AUBM-6-NS in acetone upon addition of $\mathrm{As}^{3+}$ solution followed by addition of $\mathrm{Pd}^{2+}$ solution

A

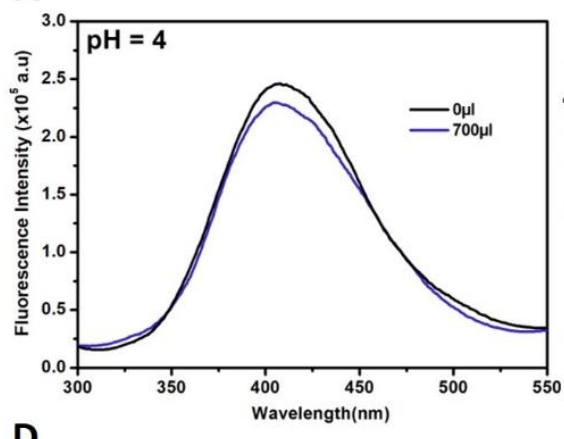

D

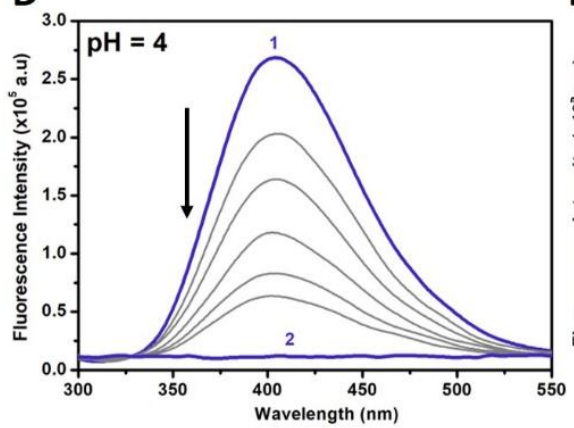

B

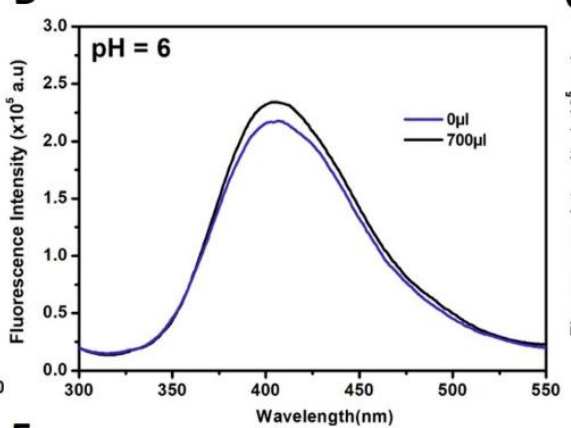

E

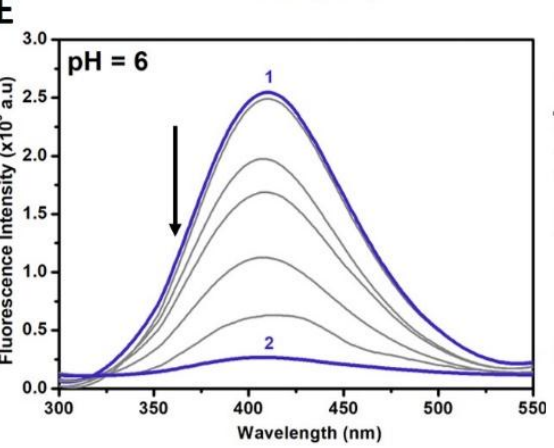

C

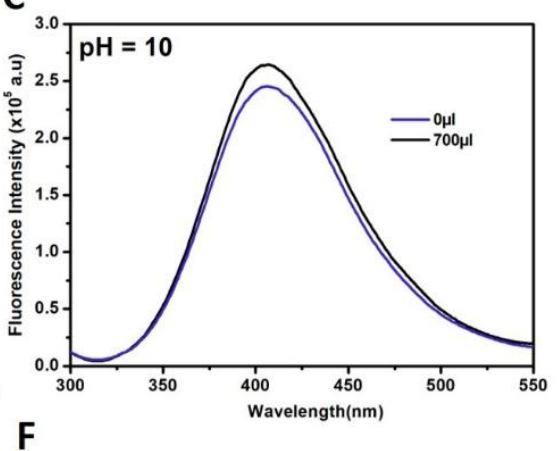

$\mathbf{F}$

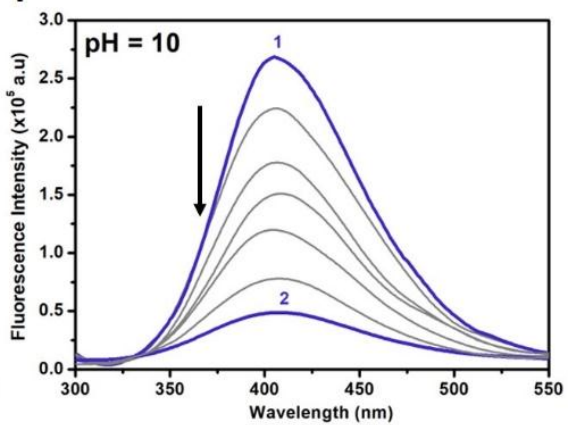

Fig. S13. Control experiments upon the addition of $700 \mu$ pure solutions without $\mathrm{Pd}^{2+}$ ions having (A) $\mathrm{pH}=4$ (B) $\mathrm{pH}=6$ and (C) $\mathrm{pH}=10$ (D)(E)(F) Quenching experiments having $\mathrm{Pd}^{2+}$ ions in corresponding $\mathrm{pH}$ solutions upon addition of (1) $0 \mu \mathrm{l}$ (2) $700 \mu \mathrm{l}$. 


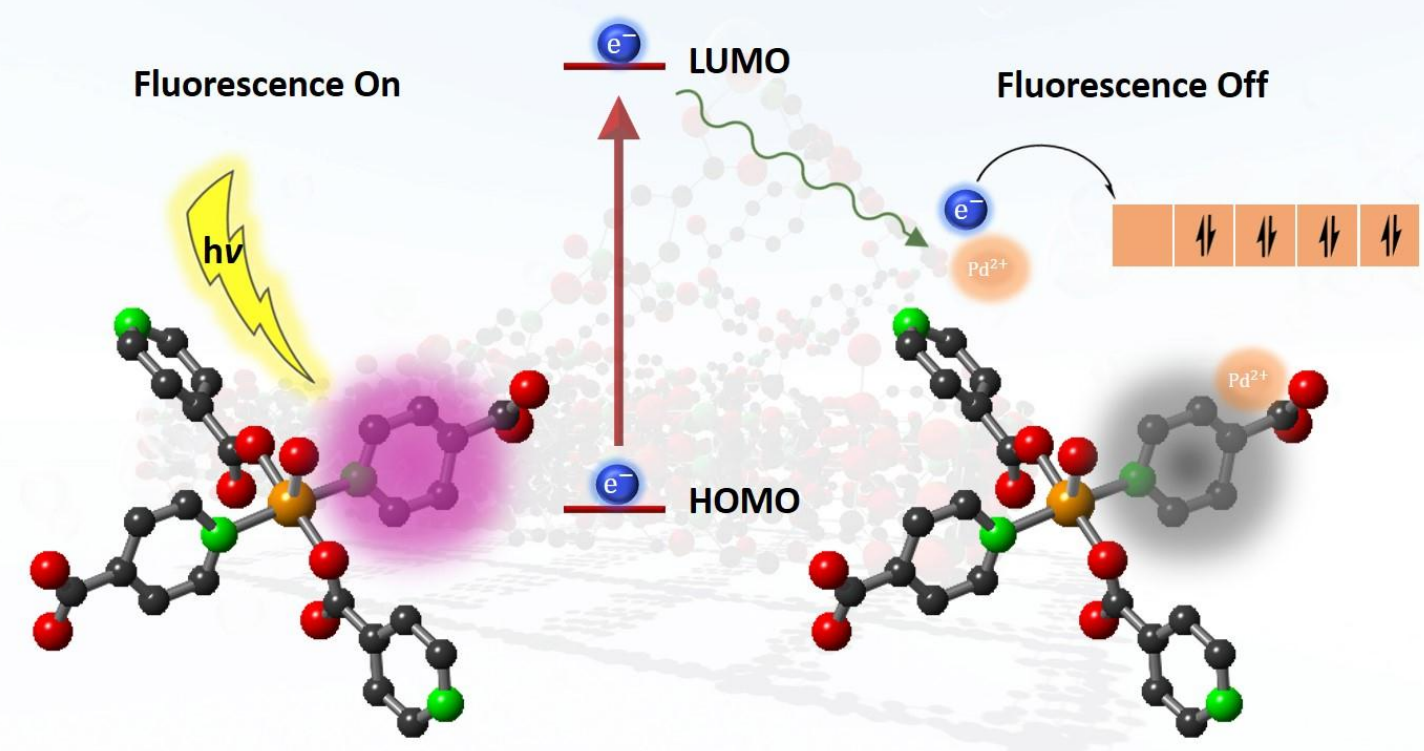

Fig. S14. Schematic presentation of the proposed pathway of the quenching mechanism of AUBM-6-NS upon the addition of $\mathrm{Pd}^{2+}$ ions 